\title{
The effects of performance measurement system uses on organizational ambidexterity and firm performance
}

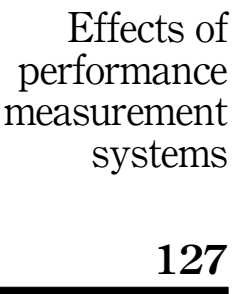

Received 13 February 2021 Revised 19 August 2021 Accepted 24 August 2021

\author{
Department of Management, University of Bologna, Bologna, Italy \\ Pietro Micheli \\ Warwick Business School, University of Warwick, Coventry, UK, and \\ Mariolina Longo \\ Department of Management, University of Bologna, Bologna, Italy
}

\begin{abstract}
Purpose - This study aims to investigate how dynamic tensions between performance measurement system (PMS) uses enable organizations to achieve both exploitation and exploration and enhance firm performance. Design/methodology/approach - The authors collected survey data on 153 Italian companies. Scales for each construct were validated through an exploratory factor analysis. Data on firm performance were crossvalidated by using lagged accounting data. The authors tested our hypotheses using hierarchical ordinary least squares regressions, together with bootstrapping procedures for the test on mediation.

Findings - A diagnostic use of PMS has a positive association with both exploitation - e.g. reductions in total costs and lead times - and exploration, e.g. introduction of new products and extension of product ranges. The dynamic tension created by a joint diagnostic and interactive use has the strongest association with organizational ambidexterity, measured as the multiplicative interaction between exploration and exploitation. Practical implications - If an organization or business unit is mainly pursuing exploitative goals, a mainly diagnostic use of PMS would be most suitable. If goals are both exploitative and explorative, a mix of diagnostic and interactive uses would be most effective.

Originality/value - This research helps reconcile conflicting views in the literature. The diagnostic use of PMS, far from acting as a "negative force," appears to be necessary to guide opportunity search and to establish an appropriate scope for exploration-related activities. The authors' focus on the uses of PMSs shows that ambidexterity is achieved through managerial capability, rather than just through the introduction of systems and structures.
\end{abstract}

Keywords Performance measurement systems, Organizational ambidexterity, Innovation, Levers of control, Firm performance

Paper type Research paper

\section{Introduction}

As organizations are increasingly required to be both flexible and efficient, and to exploit existing products and services while developing radically new ones, scholars have paid growing attention to the effects of performance measurement systems (PMSs) on organizations' capacity to innovate (Bititci et al., 2012; Koufteros et al., 2014; MüllerStewens et al., 2020). Traditionally, PMSs have been regarded as tools whose primary functions are to understand and monitor performance and ensure alignment and stability in

(C) Matteo Mura, Pietro Micheli and Mariolina Longo. Published by Emerald Publishing Limited. This article is published under the Creative Commons Attribution (CC BY 4.0) licence. Anyone may reproduce, distribute, translate and create derivative works of this article (for both commercial and noncommercial purposes), subject to full attribution to the original publication and authors. The full terms of this licence may be seen at http://creativecommons.org/licences/by/4.0/legalcode

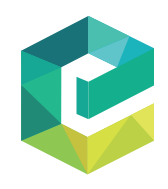

International Journal of Operations \& Production Managemen Vol. 41 No. 13,2021 pp. 127-151 Emerald Publishing Limite DOI 10.1108/IJOPM-02-2021-0101 
IJOPM

41,13

organizations (Melnyk et al., 2004; Henri, 2006). However, more recent research emphasizes the role of a PMS in supporting, rather than necessarily constraining, different types of innovation (e.g. Bititci et al., 2018; Henri and Wouters, 2020). At the same time, how different designs and uses of PMSs affect innovation is still unclear (Bititci et al., 2012; Koufteros et al., 2014; Müller-Stewens et al., 2020).

This study investigates whether and how different uses of a PMS enable organizations to become ambidextrous and to enhance firm performance. In line with previous work, we conceptualize organizational ambidexterity as an organization's capacity to both exploit existing processes and resources while exploring new opportunities and radically innovate its products (March, 1991; Raisch and Birkinshaw, 2008; Kortmann et al., 2014). Despite the abundance of studies in this field, several scholars have emphasized that little is known as to which management systems and processes can facilitate the achievement of organizational ambidexterity (O’Reilly and Tushman, 2011; Birkinshaw and Gupta, 2013; Bedford et al., 2019).

In this study, we consider PMSs as mechanisms that top management teams can deploy to link strategy and operations and to promote behaviors and actions consistent in line with the organization's goals (Hanson et al., 2011; Micheli and Mura, 2017; Bedford et al., 2019). Moreover, drawing on the recent research adopting the levers of control framework (Simons, 1995; Pešalj et al., 2018), we regard different PMS uses, and the dynamic tensions between them, as potential enablers of exploitation and exploration. Consistently with previous research (e.g. Bisbe and Otley, 2004; Henri, 2006; Koufteros et al., 2014; Chenhall and Moers, 2015), we focus on two uses, diagnostic and interactive [1]; the former referring to the traditional view of measurement as tracking and reviewing performance data related to organizational goals; the latter referring to the future-looking use of performance data, associated communication processes and the mutual adjustment of organizational actors (Henri, 2006).

While some scholars have investigated PMSs' roles in either enabling or hindering innovation, the findings are limited and often conflicting. Some studies shows that a diagnostic use is negatively related to innovation (Henri, 2006; Simons, 1995), whereas others conclude the opposite (e.g. Koufteros et al., 2014). When focusing on the effects of the interactive use, some identify positive effects on innovation (Henri, 2006; Koufteros et al., 2014), whereas others do not (e.g. Bisbe and Otley, 2004). Therefore, in this study, we investigate the roles of the diagnostic and interactive uses of PMSs in supporting the management of paradoxical tensions between exploitation and exploration, and, ultimately, in enhancing firm financial and non-financial performance.

Empirically, we conduct a survey of 153 Italian firms completed by company chief executive officers (CEOs) or chief finance officers (CFOs). Our results help reconcile conflicting views and advance scholarly understanding in both operations management and organization theory. First of all, contrary to expectations, our findings portray the relationship between diagnostic and interactive as one of synergy, rather than of opposition. Also, the sole interactive use is found to have a very limited impact over exploration. Furthermore, we demonstrate that the "dynamic tension" (Simons, 1995) created by the interplay between diagnostic and interactive uses of PMSs enables the achievement of organizational ambidexterity. In so doing, this study contributes to the organization theory by emphasizing the importance of stability and formalization for different types of innovation (Jansen et al., 2006; Smith and Besharov, 2019). By considering the uses of PMSs, it also supports the argument whereby ambidexterity is attained through managerial capability, rather than through the introduction of systems and structures, such as the mere deployment of a new control system (Birkinshaw and Gupta, 2013). Moreover, this study contributes to the literature on the effects of a PMS (Franco-Santos et al.,2012) by showing that the impact of a PMS uses on firm performance is mediated by organizational ambidexterity. 
The paper is structured as follows: it first reviews the organizational ambidexterity and performance measurement literatures focusing on similarities among the two, as expressed by the concepts of paradox and of dynamic tension among PMS uses. It then develops research hypotheses that relate performance measurement system uses, organizational ambidexterity and firm performance. Subsequently, it presents the method and findings from the survey. The paper concludes by highlighting the main contributions and implications of the study to both theory and practice.

\section{Theoretical background}

\subsection{Organizational ambidexterity and paradox}

March's (1991) article on organizations' capacity to explore new possibilities, while exploiting existing assets and knowledge, is often cited as a seminal paper in the organizational ambidexterity literature. Essentially, exploitation refers to building on extant knowledge, emphasizing current customer preferences and improving existing offerings (Raisch and Birkinshaw, 2008), whereas exploration indicates an organization's capacity to investigate and pursue new opportunities, develop new knowledge and radically innovate its products and services (Benner and Tushman, 2015).

Extant research shows that the singular pursuit of exploitation yields diminishing returns and can lead to various dysfunctional consequences, as it may make an organization incapable of adapting to changing conditions. Exploitation may also lead to a "success trap" (Gupta et al., 2006), as it is often triggered by early success, which in turn reinforces further exploitation along the same trajectory. A sole focus on exploration would not be appropriate either, because, at best, it may lead to inefficiency and the inability to build on previous successes and, at worst, it can make an organization collapse. Indeed, Gupta et al. (2006, p. 695) concluded that "because of the broad dispersion in the range of possible outcomes, exploration often leads to failure, which in turn promotes the search for even newer ideas and thus more exploration, thereby creating a 'failure trap."

Scholars agree that achieving exploitation and exploration concurrently is challenging, because the objectives of each activity are often in conflict, and they tend to be iteratively selfreinforcing. While an organization should engage sufficiently in exploitation to guarantee its current viability and at the same time fund exploration-related activities that can ensure its future viability (March, 1991), exploitation requires standardization, formalization, specialization and hierarchy, which may hinder the organization's capacity to explore and adjust over time. Indeed, several authors have argued that what makes a company a "disciplined machine" is directly opposite to what it needs to be successful in the long run (Benner and Tushman, 2015).

Other scholars, while acknowledging key differences between exploration and exploitation, have adopted a paradoxical framing to study organizational ambidexterity. In this context, paradox denotes a persistent contradiction between interdependent elements, rather than their inherent opposition (Andriopoulos and Lewis, 2009; Bedford et al., 2019). Thus, a paradox cannot be resolved, as its "core elements remain, impervious to resolution" (Schad et al., 2016, p. 11); however, tension between elements can be understood and managed, and competing goals - such as the exploitation of current offerings and the exploration of new ones - can be achieved simultaneously, at least to some extent. A paradoxical framing is also concerned with how organizations can address competing demands at the same time (Smith and Lewis, 2011), rather than examining separately the conditions under which one set of activities (e.g. innovation, flexibility) or another (e.g. efficiency, standardization) can be effective (Tamayo-Torres et al., 2017). Therefore, conceptualizing organizational ambidexterity as a paradox entails reconsidering which support mechanisms can be used to promote exploitation and exploration. While past research mainly argued for the creation

\section{Effects of performance measurement systems}


IJOPM

41,13

and deployment of separate structures, processes and systems to promote exploitative and exploratory activities (Lavie et al., 2010), scholars have increasingly called for the identification of integrated approaches and systems that enable synergies between the two (Schad et al., 2016). However, little is known as to what these approaches and systems specifically are (Raisch and Birkinshaw, 2008; Bedford et al., 2019).

\subsection{Different uses of performance measurement systems and dynamic tensions among them}

Over the past years, an increasing number of studies have been conducted on the roles and effects of performance measurement systems (see, e.g. Franco-Santos et al., 2012; Bititci et al., 2018, for reviews). A major result of this research is that, while specific aspects related to the quality of the measurement system itself matter (e.g. accuracy and precision of performance data, appropriateness of performance targets), how PMSs are used is fundamentally important. In particular, several authors have referred to Simons' "levers of control" framework (Simons, 1995), which states that PMSs, and other types of management control systems, can be used in four ways - as beliefs systems, boundary systems, diagnostic systems and interactive systems (Pešalj et al., 2018). While all four "levers" play important roles, several authors have considered only two of them: diagnostic and interactive (see, e.g. Bisbe and Otley, 2004; Henri, 2006; Koufteros et al., 2014; Chenhall and Moers, 2015). The diagnostic use refers to monitoring outcomes against pre-defined targets and correcting deviations, whereas the interactive use concerns the utilization of performance data to stimulate dialogue and promote learning, also to develop new strategic goals (Heggen and Sridharan, 2021).

While each use has specific characteristics and effects, several authors have also investigated the "dynamic tensions" existing among them, especially in relation to innovation (e.g. Henri, 2006; Koufteros et al., 2014; Pešalj et al., 2018). Indeed, Simons (1995) stated that organizations should use their control systems - such as PMS - in combination to generate a "dynamic tension" that promotes both predictable goal achievement and innovation and strategic change. This tension has been described as "dynamic" because "there are continual and varied strategic forces acting both internally and externally ... encapsulated in a set of organizational conflicts that impact the capacity of organizations to balance controlling and enabling uses" of PMSs (Mundy, 2010, p. 502).

Some authors have emphasized that the combination of different uses of PMS could help organizations balance competing objectives. For example, Müller-Stewens et al. (2020) identify that diagnostic control, aimed at ensuring that an organization is achieving its predefined objectives, can positively influence the efficiency of new product development processes in research and development (R\&D)-intensive firms, whereas interactive control, aimed at stimulating opportunity-seeking behavior across persons and activities, can have a positive effect on creativity. Considering the interdependence between levers, Bedford (2015) concludes that diagnostic and interactive uses have joint effects on performance, but that these depend on the type of innovation being pursued. Investigating whether PMSs can facilitate the realization of ambidextrous strategies, Bedford et al. (2019) find that diversity of performance indicators is positively associated with competence ambidexterity, intended as the acquisition of competences in both exploration and exploitation.

While these results certainly advance scholarly understanding of PMSs' roles in either enabling or hindering innovation, there are limited and sometimes conflicting findings over the specific ways in which PMSs can be used to do so. For instance, Henri (2006) concludes that a diagnostic use of PMSs is negatively related to innovativeness, in line with Simons' (1995) original view that diagnostic control systems "constrain innovation and opportunityseeking to ensure predictable goal achievement needed for intended strategies" (p. 91). By contrast, Koufteros et al. (2014) identify that a diagnostic use has a more positive effect on innovativeness than an interactive one. Considering the relationship between an interactive 
use of PMSs and innovation, both Henri (2006) and Koufteros et al. (2014) find evidence of positive effects, whereas Bisbe and Otley (2004) do not, and Bedford (2015) concludes that these vary according to an organization's main approach to innovation.

Some studies have also explored how the relationship between PMS and innovation shapes the impact of PMS uses on firm performance. For example, Koufteros et al. (2014) find that diverse uses of PMSs lead to improved capabilities such as innovativeness, which, in turn, positively affect firm performance. Similarly, Bedford (2015) finds evidence that the association between uses of control systems and firm performance varies across different innovation modes. At the same time, Henri (2006) hypothesizes an indirect effect of PMS use on performance through four capabilities, including innovativeness, but this relationship is found to be not significant. On the basis of these and other studies on the effectiveness of PMSs, several authors have called for further research that sheds light on the ways in which PMSs affect firm performance (Guenther and Heinicke, 2019), considering innovation-related aspects as key factors (Franco-Santos et al., 2012).

\section{Hypotheses development}

This research examines whether and how PMS uses, and the dynamic tension among them, enable organizations to achieve organizational ambidexterity and, ultimately, improve firm performance. In particular, we will test three sets of hypotheses.

\subsection{PMS uses and exploitation}

A diagnostic use of PMSs "represents a mechanistic control used to track, review and support the achievement of predictable goals" (Henri, 2006, p. 533). It tends to fulfil a traditional feedback role as measurement systems are utilized to monitor and correct deviations from established performance targets and to reward their achievement (Melnyk et al., 2004; Bititci et al., 2018). A diagnostic use has also been associated to the monitoring, communication and implementation of intended strategies (Bourne et al., 2000; Guenther and Heinicke, 2019). As a consequence, some scholars have claimed that a PMS used diagnostically acts as a "negative force" because it promotes a focus on mistakes and negative variances through single-loop learning (e.g. Henri, 2006; Simons, 1995). At the same time, it could be argued that the diagnostic use could support the pursuit of exploitation as it enables a better understanding of current processes and performance, which can help reduce lead times and costs and promote continuous improvement. Indeed, initial evidence shows that PMSs utilized diagnostically positively affect performance in firms aiming to exploit existing markets and technological capabilities (Bedford, 2015). Therefore, in this study, the diagnostic use of PMSs is regarded as a means to track progress toward goals, help monitor results and compare them to expectations. In doing so, it encourages the attainment of exploitative goals, such as improving existing product quality and current processes, by creating constraints, promoting continuous improvement through single-loop learning (Widener, 2007) and helping manage the innovation process (Müller-Stewens et al., 2020). Therefore, it is hypothesized that:

H1a. A diagnostic use of PMSs is positively associated with exploitation.

An interactive use of PMSs is consistent with an organic, rather than mechanistic, view of control systems (Henri, 2006), as it fulfils a feed-forward role by promoting communication within the organization and the mutual adjustment of organizational actors (Bisbe and Otley, 2004; Grafton et al., 2010). An interactive use is not concerned with the reporting of discrepancies between expected and actual performance; rather, it is related to more emergent communication, particularly when forward-looking and concerned with novel opportunities

\section{Effects of performance measurement systems}


IJOPM

41,13

or ways of doing (Koufteros et al., 2014; Bedford, 2015). In contraposition with diagnostic, it has been described as a "positive force" since PMSs are deployed to support the search for new opportunities and the development of ideas as well as to trigger double loops of learning across the organization (Henri, 2006). Indeed, Simons (1995) asserted that the interactive use can foster creativity at individual and collective levels. At the same time, an interactive use of PMSs may not contribute to, or it may even negatively affect, an organization's capacity to improve its existing processes and offerings. To use measurement systems interactively requires resource commitments and entails continuous discussions over performance data, current assumptions and action plans with the aim of introducing changes to processes and offerings. Thus, it may consume management time and attention, and potentially lead to inefficient resource allocation (Widener, 2007). This, in turn, may undermine the very use of those practices aimed at improving performance, thereby hindering the exploitation of current resources, processes and offerings. Hence, it is expected that:

H1b. An interactive use of PMSs is negatively associated with exploitation.

\subsection{Performance management system uses and exploration}

A diagnostic use of PMSs has been considered unrelated to, if not negatively affecting, an organization's capacity to explore new technologies and introduce novel offerings (Bititci et al., 2018). Indeed, in Simon's original work (1995), consistently with the traditional cybernetic type of controls (Chenhall and Moers, 2015), the diagnostic use was portrayed as constraining the search for opportunities as it focuses attention on current goals, processes, products and services. Similarly, other authors have highlighted its role in restricting risktaking, reducing individual- and team-level creativity, and in triggering discussions that lead to corrective action at best (Henri, 2006). Recently, authors have also argued that excessively using PMSs in a diagnostic way could jeopardize an organization's capacity to innovate (Bedford, 2015; Chen et al., 2020). Building on these studies, it is hypothesized that:

H2a. A diagnostic use of PMSs is negatively associated with exploration.

An interactive use has been described as a means to "build internal pressure to break out of narrow search routines, stimulate opportunity-seeking, and encourage the emergence of new strategic initiatives" (Simons, 1995, p. 93). Several authors have argued that utilizing PMSs interactively could enhance an organization's capacity to explore new technologies and markets, and develop new products and services through the development of new ideas and initiatives within the firm (Henri and Wouters, 2020). Empirical studies have concluded that an interactive use can help organizations become more innovative and derive greater benefits from innovation (e.g. Bisbe and Otley, 2004; Pešalj et al., 2018), because it facilitates goalsetting and the creation of novel action plans (Grafton et al., 2010). Moreover, it can promote the exchange of tacit knowledge in an organization and support decisions over which initiatives to pursue (Bedford, 2015). Utilizing PMSs interactively can also contribute to expanding an organization's information processing capacity and fostering interaction between organizational actors (Henri, 2006). This is because it tends to foster double-loop learning by promoting dialogue throughout the organization and challenge current assumptions and action plans, thereby supporting the organization's efforts in launching new products (Henri, 2006). Therefore, an interactive use is likely to lead to the attainment of exploratory goals, such as opening new markets and entering new technology fields. Hence, it is expected that:

H2b. An interactive use of PMSs is positively associated with exploration.

An overview of the theoretical model related to the first and second set of hypotheses is presented in Figure 1. 
3.3 The mediating effect of organizational ambidexterity between performance management system uses and firm performance

Over the past two decades, several studies have investigated the effects of performance measurement systems on firm performance, both financial and non-financial (e.g. FrancoSantos et al., 2012; Koufteros et al., 2014; Micheli and Mura, 2017). Empirical findings show that effects vary considerably and depend on a variety of factors, including whether performance indicators are related to strategy, and whether cause-and-effect links between objectives and indicators are explicitly articulated (Melnyk et al., 2004; Guenther and Heinicke, 2019). A growing body of literature emphasizes that the link between PMSs and firm performance can be explained not only by considering how PMSs are designed and structured, but in particular by how they are used.

For example, Henri (2006) finds that the dynamic tension between diagnostic and interactive uses has a positive impact on financial performance - measured using three indicators: sales volume, return on investment and profits - because the ability to stimulate innovation and search for predictable achievements at the same time constitutes a capability, which is valuable, distinctive and imperfectly imitable. Widener (2007) identifies a positive relationship between PMS uses and firm financial and non-financial performance - measured as overall profitability, market share and productivity of the delivery system - as the benefits deriving from the combined uses of PMSs outweigh their costs by positively impacting management attention and organizational learning. In line with Henri (2006), Grafton et al. (2010) conclude that different uses of PMS serve two distinct purposes in supporting strategy development and execution, and that striking a balance between uses enables organizations to support both current and future capabilities and, in turn, enhance firm financial performance.

Koufteros et al. (2014) find that high levels of both diagnostic and interactive uses have a positive effect on strategic management, operational and external stakeholder relations capabilities and, as a result, on firm performance, both financial and non-financial. Bedford (2015) concludes that the interaction between diagnostic and interactive uses has a positive and significant association with firm financial performance particularly in ambidextrous firms. Therefore, building on the literature on the effects of PMSs on firm financial and nonfinancial performance, the following hypothesis is proposed:

$H 3 a$. The interaction between diagnostic and interactive uses is positively associated with firm performance.

In line with the literature on organizational paradox and on the uses of PMSs (Henri, 2006; Bedford et al., 2019), this study considers a PMS uses as mechanisms to support the achievement of organizational ambidexterity. In particular, the capacity to promote alignment and control, while also stimulating strategic dialogue and innovation is proposed as a key means to manage the tension between the exploitation of resources,

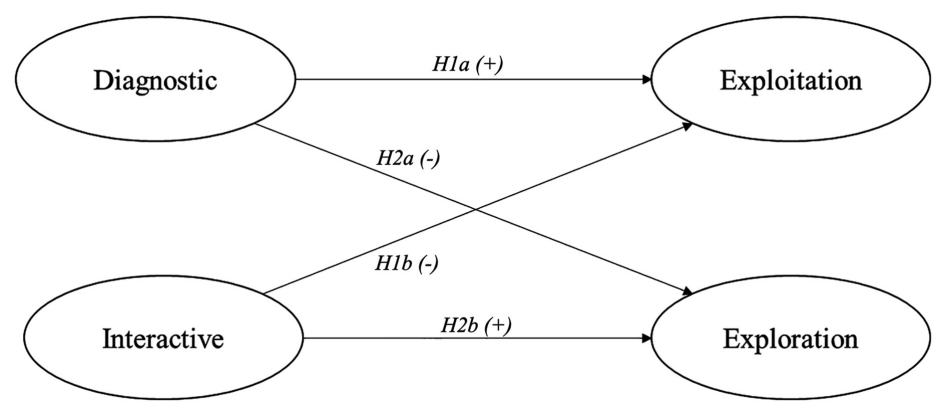

Figure 1. Theoretical model for sets of $\mathrm{H} 1$ and $\mathrm{H} 2$ 
IJOPM

41,13

134

technologies and offerings, and the exploration and introduction of new ones (Bedford et al., 2019). Moreover, the joint diagnostic and interactive uses of PMSs are seen as triggering both feedback and feedforward loops of learning (Grafton et al., 2010) and as supporting the creation of a both/and perspective, rather than an either/or one (Andriopoulos and Lewis, 2009), thus leading to the simultaneous consideration of opposing positions (Bedford, 2015).

The combination of uses and the consideration of the dynamic tensions among them are fundamental in this context, as some authors conclude that an insufficient diagnostic use of PMSs may hinder the effects of an interactive one on organizations' efforts to achieve radical innovation, due to lack of stability, standardization and clear direction (see Henri, 2006; Bedford et al., 2019; Müller-Stewens, 2020). Similarly, Widener (2007) finds that, when considering the link between PMS uses and organizational learning, the interactive has a significant effect only through the diagnostic use, but not on its own. Therefore, in this study, we focus on the dynamic tension generated by the combined use of PMSs and hypothesize its direct, positive impact on organizational ambidexterity:

H3b. The interaction between diagnostic and interactive uses is positively associated with organizational ambidexterity.

The organizational ambidexterity literature posits that firms, which are aligned toward their current goals but are at the same time flexible to adapt rapidly to changing future demands, can achieve higher performance outcomes (Raisch and Birkinshaw, 2008; Kortmann et al., 2014). Although this may be regarded as a fundamental reason for the "explosion of interest" (O'Reilly and Tushman, 2013) in organizational ambidexterity witnessed over the past two decades, evidence over the relationship between ambidexterity and firm performance is not conclusive (Jancenelle, 2020). In one of the earliest empirical investigations, Gibson and Birkinshaw (2004) found that a business unit's capacity to foster both alignment and adaptability was significantly related to its performance outcomes, both financial and nonfinancial. Lubatkin et al. (2006) also concluded that simultaneously pursuing exploitation and exploration has a positive effect on firm financial performance. While similar findings have been subsequently drawn by other authors, no definitive conclusions could be reached in relation to both financial (e.g. growth and profitability) and non-financial performance (for a review, see Junni et al., 2013). However, in this study, we follow prior research that has conceptualized organizational ambidexterity as an organization's ability to achieve both exploitation and exploration, and thus as a means to avoid both "success" and "failure traps" (Gupta et al., 2006). Moreover, we draw on Uotila et al. (2009) who found that the balance between exploitation and exploration is more beneficial to firm performance than emphasizing either dimension. Therefore, we hypothesize that:

H3c. Achieving organizational ambidexterity has a positive effect on firm performance.

On the basis of the research findings reviewed in support of the previous three hypotheses, this study further posits that:

H3d. Organizational ambidexterity mediates the relationship between combined PMS uses and firm performance.

An overview of the theoretical model related to the third set of hypotheses is presented in Figure 2 .

\section{Research method}

4.1 Procedures and sample

To test the proposed hypotheses, we collected data through a survey of Italian companies [2]. To do so, we contacted the Italian Association of Chief Financial Officers, which agreed to 


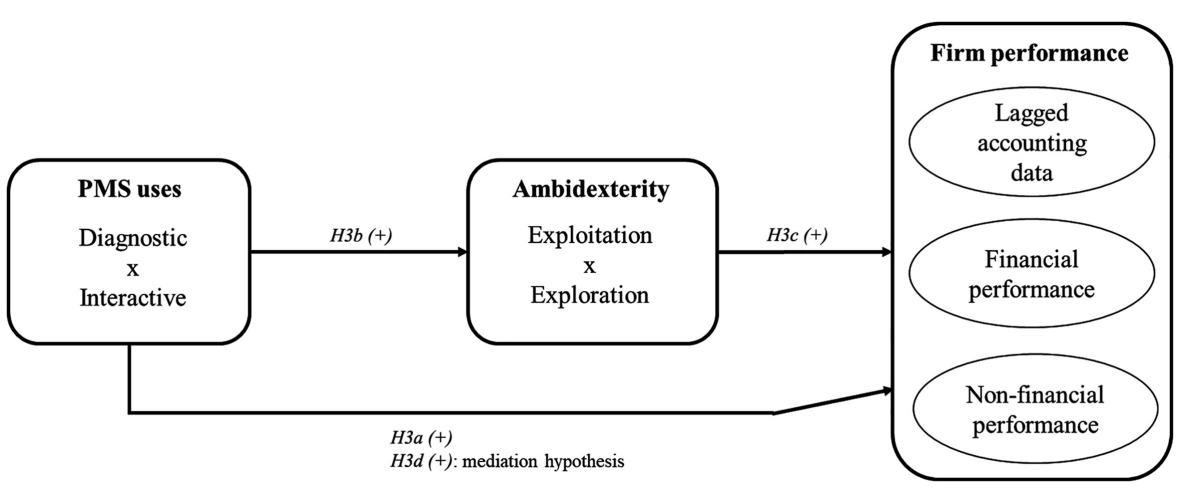

Effects of
performance
measurement
systems

135

Figure 2.

Theoretical model for $\mathrm{H} 3$ on mediation

participate in the study and to send our survey to all its 1,563 member organizations. Introductory letters, endorsed by the Director of the Association, were written to outline the research topic, encouraged participation, promised that each participating company would receive a summary of the findings and indicated that we would send the questionnaire via e-mail. Following previous studies in this field (Micheli and Mura, 2017; Pedersen and Sudzina, 2012; Upadhaya et al., 2014), the questionnaire was directed to either the CFO, the $\mathrm{CEO}$ or the managing director. Given that a large number of Italian companies are small or medium-sized firms, the roles of $\mathrm{CEO}, \mathrm{CFO}$ and managing director sometimes coincide. Additionally, the organizational hierarchy of these small firms is usually quite flat, and therefore, these respondents also have an operational-level knowledge of the firm and can appropriately provide information related to specific aspects of the performance measurement approach. Overall, selecting these respondents enabled us to receive wellinformed responses on PMSs, exploitative and explorative activities, and firm performance (Lubatkin et al., 2006). Six months later, we conducted a follow-up survey on the companies that had not previously answered. Overall, 153 firms provided useable questionnaires, thus representing a response rate of $10 \%$, comparable to similar studies in this field.

Firms in the final sample have an average size of 4,977 $(\mathrm{SD}=19,546)$ full-time equivalent employees and operate in a wide range of industries including manufacturing $(28.4 \%)$, automotive $(12.6 \%)$, food $(9.6 \%)$, Information and communications technology $(9.0 \%)$, chemical $(8.0 \%)$ and other industries. Furthermore, $67 \%$ of the firms have a turnover higher than $€ 50 \mathrm{~m}, 6 \%$ lower than $€ 10 \mathrm{~m}$. To test for nonresponse bias, we examined the differences between respondents and non-respondents in our final sample. $T$-tests showed no significant differences based on the number of full-time employees and turnover. We also compared early and late respondents in terms of demographics and model variables. These comparisons did not reveal any differences $(p<0.05)$, showing that nonresponse bias was not a problem. Finally, we also explored differences in responses between CEOs, CFOs and managing directors, and no statistically significant difference emerged.

\subsection{Measures}

All constructs were measured with multi-item scales. Scores on these measures were means calculated across items. Scales for each construct were derived from extant literature, and modifications were made to adapt measures to the empirical context. Adapted scales were pretested on a small sample of managers to ensure that their meaning was clear. Using our final sample, we conducted numerous analyses, described below, to verify that our measures were sound. The survey questionnaire is reported in the Appendix, together with the results of the exploratory factor analyses (EFAs). 
IJOPM

41,13

4.2.1 Firm performance. Firm performance is a multidimensional construct; since PMS uses and organizational ambidexterity may have different effects depending on what aspect of performance we consider (Junni et al., 2013), we measured firm performance in three ways: perceived non-financial performance, perceived financial performance and financial performance using lagged accounting data.

Non-financial performance was measured with four items adapted from Gibson and Birkinshaw (2004) that required respondents to reflect on their firm's performance over the previous five years and indicate the degree to which they agreed with statements such as: "this firm is achieving its full potential" and "this firm does a good job at satisfying our customers." The scales range from 1 (completely disagree) to 7 (completely agree).

Firm financial performance was measured with a three-item scale, adapted from Reinartz et al. (2004) and Jaworski and Kohli (1993), which required respondents to assess their firm performance relative to competitors over the previous five years in relation to market share, sales growth and current profitability. The scales range from 1 (much less) to 7 (much more).

The evaluation of financial performance by CEOs, CFOs or managing directors was necessary in some cases, since $43 \%$ of the companies in our sample are SMEs for which accounting data on financial performance are not always available, largely because the owners are not legally required to publish them. At the same time, and despite evidence that suggests that self-reports of performance by CEOs and CFOs significantly correlate with some accounting measures of firm performance, we decided to collect firms' accounting data on return on investment (ROI) from Amadeus (a Bureau van Dijk database) on a subsample of firms $(N=101)$, for which accounting data were available, over the two financial years following our survey. As suggested by several scholars (e.g. He and Wong, 2004), ROI is a commonly used proxy for firm financial performance, because it assesses how efficiently a firm uses its resources. Moreover, ROI has the added benefit of not requiring to explicitly control for firm size, because it is a size-adjusted ratio. We decided to collect annual data for each firm during a two-year period because we wanted to capture potential time lags and reduce annual fluctuations in the ROI data. Consistently with prior research (e.g. Rothaermel, 2001), we then averaged the ROI data obtained over this timeframe to create a financial performance index. We applied a logarithmic transformation to enhance the normality of the variable's underlying distribution.

Finally, we correlated this measure of firm financial performance based on lagged accounting data with our perceptual measures of firm performance and found positive and significant correlations with both Non-financialperformance $(r=0.20, p<0.05)$ and Financial performance $(r=0.16, p<0.05)$. This association is consistent with previous studies in the ambidexterity literature that employed similar techniques to cross-validate perceptual measures of firm performance (e.g. He and Wong, 2004; Lubatkin et al., 2006). Importantly, this finding provides evidence of the external validity of the self-reported measure used.

4.2.2 Organizational ambidexterity. As previously mentioned, in line with previous studies (e.g. Gibson and Birkinshaw, 2004; He and Wong, 2004; Lubatkin et al., 2006), we consider ambidexterity to be a multidimensional construct. We thus used separate scales for exploration and exploitation. Respondents were asked to assess their firm's orientation during the previous five years relative to their competitors using a scale ranging from 1 (much worse) to 7 (much better). The measures we selected are adapted from Lubatkin et al. (2006) and Villena et al. (2011) and are related to the outcomes of the exploration and the exploitation processes. For example, items consistent with exploration describe the firm as one that "introduces new generation of products" and "enters new technology fields." Items consistent with exploitation describe the firm as one that aims to "reduce total costs" and to "improve current processes."

When modeling organizational ambidexterity, some studies have regarded exploration and exploitation as poles on a continuum, and ambidexterity as an optimal point on such 
continuum (e.g. Lavie et al., 2010). Others, instead, have considered exploration and exploitation as independent activities, and ambidexterity as the combination of the two (e.g. Birkinshaw and Gupta, 2013). Interestingly, Cao et al. (2009) explicitly tested the effects of either balancing or combining exploration and exploitation (i.e. similar levels vs their interaction), and found that both were positively associated with firm performance. Importantly, these authors also indicated that unpacking the ambidexterity construct into distinct dimensions could explain previously unaccounted-for variance in firm performance.

In this study, while we consider exploration and exploitation as separate dimensions, and ambidexterity as firms' ability to consistently deliver on both at the same time (Birkinshaw and Gupta, 2013), we do not underestimate the inherent trade-offs between them, nor do we see them as complementary (Lavie et al., 2010). Rather, we argue that exploration and exploitation are not necessarily in opposition (Gupta et al., 2006). We, therefore, modeled organizational ambidexterity as the multiplicative interaction between exploration and exploitation, reflecting the argument that these two organizational capabilities are nonsubstitutable and interdependent. Following Cao et al. (2009) and Lubatkin et al. (2006), the interaction model was chosen after comparing, by means of confirmatory factor analyses, three different models presenting the relation between exploration and exploitation as an interaction, a sum, or a subtraction.

4.2.3 Performance management system use. We considered PMS use as a multidimensional construct comprising of diagnostic and interactive uses. We thus constructed separate scales, adapting them from Henri (2006). Respondents were asked to rate, using a scale ranging from 1 (totally disagree) to 7 (completely agree), how PMSs were used in their firms. For instance, items consistent with diagnostic use describe performance measures as being used to "track progress towards goals" and "monitor results." Items related to interactive use describe performance measures as being used to "enable discussion in meetings between managers and employees or among peers" and "enable continual challenge and debate underlying data, assumptions and action plans." Coherently with Henri (2006) and Koufteros et al. (2014), we modeled the dynamic tension between interactive and diagnostic uses of PMSs as the multiplicative interaction term between these two measurement scales.

4.2.4 Control variables. We controlled for a number of theoretically relevant factors. Because larger companies may have more resources, but they may lack the flexibility to explore (Jansen et al., 2006), we included the natural logarithm of the number of full-time employees within the firm to account for company size. We also controlled for four additional organizational variables: we adapted two scales from Cesaroni (2004) to capture a firm's degree of technological diversification and its level of product differentiation, since both may be associated with higher levels of exploration. We included a scale for the degree of internationalization (adapted from Lord and Ranft, 2000) that captures the number and importance of a firm's foreign subsidiaries as it may be positively related to an organization's propensity to explore new knowledge domains. We controlled for the amount of slack resource available in a firm by adapting the scale proposed by Nohria and Gulati (1996), because higher slack resources may positively correlate with a firm's exploration.

Previous studies have found that environmental variables significantly moderate the relationship between PMSs and innovation (e.g. Henri and Wouters, 2020; Müller-Stewens et al., 2020). Therefore, we also controlled for three further variables: environmental dynamism (adapted from Jansen et al., 2006), environmental competitiveness and technological turbulence (both adapted from Jaworski and Kohli, 1993). All these variables are measured as Likert-type scales ranging from 1 (totally disagree) to 7 (completely agree).

\section{Effects of performance measurement \\ systems}


IJOPM

41,13

\section{Results}

\subsection{Scale validity and reliability}

EFA was used to validate the variables used in this study. We firstly conducted an EFA on the 25 items measuring the six focal constructs of our study (i.e. diagnostic use, interactive use, exploitation, exploration, non-financial performance, financial performance). The six factors that emerged from the analysis accounted for $70.83 \%$ of the variance, and appropriately represented firm non-financial and financial performance, exploration and exploitation, diagnostic and interactive uses. Primary loadings exceeded 0.57, and the difference among cross-loadings were higher than 0.30 . Adequate reliabilities were achieved for all constructs with a Cronbach's $\alpha$ coefficient higher than 0.74 (Nunnally, 1978). These results suggest adequate convergent validity, discriminant validity and reliability of the proposed measures (Kim and Muller, 1989). The results of this EFA are reported in Table A1 of the Appendix. Overall, the EFA conducted led to the exclusion of one hypothesized item in the non-financial performance scale.

We conducted a second EFA on the seven control variables proposed in the previous section, and the results show good psychometric properties of the proposed scales in terms of convergent validity, discriminant validity and reliability (the results of the EFA on the control variables are available upon request). Table 1 reports the Cronbach's alpha coefficients, together with correlations and descriptive statistics.

Financial and non-financial performance are positively related to exploration and exploitation, as well as diagnostic and interactive uses $(p<0.001)$. Control variables such as technological turbulence and technological diversification are positively related to the dependent variables of our study $(\phi<0.01)$, while the other control variables show mixed associations.

\subsection{Same source bias}

Since most data are self-reported and the same individual answered questions related to both dependent and independent variables, common method bias was a concern. Following Podsakoff et al. (2003), we took procedural measures to minimize the impact of common method bias by randomizing the sequence of items in the survey, guaranteeing confidentiality to respondents, emphasizing that there were no correct or incorrect answers and asking respondents to provide independent and honest answers.

In addition, to evaluate the extent to which common method bias might influence our empirical findings, we carried out various post hoc tests on the data. First, Harman's singlefactor test was conducted on the conceptually crucial variables of our theoretical model (i.e. firm non-financial performance and financial performance, exploration and exploitation, and diagnostic and interactive uses of PMSs). The outcome of this test showed that there are six factors, and that the highest variance accounted for by one factor is $32 \%$, indicating minimal evidence of common method bias.

\subsection{Hypotheses tests}

We tested the first two sets of hypotheses using hierarchical ordinary least squares (OLS) regressions. The third set of hypotheses on mediation was tested by following the procedure proposed by Zhao et al. (2010). Following Peltokorpi et al. (2020), we also applied a bootstrapping procedure with 5,000 replications (Preacher and Hayes, 2004) to further support our mediation hypothesis.

Table 2 shows regression results for the effects of PMS uses on exploitation (H1a, b). Our results provide support for H1a, which suggests that a diagnostic use of PMSs positively affects an organization's exploitation $(\beta=0.307 ; p<0.001)$. However, H1b, which predicts that an interactive use of PMSs negatively affects an organization's capacity to exploit, is not supported $(\beta=0.056 ; p>0.10)$. 


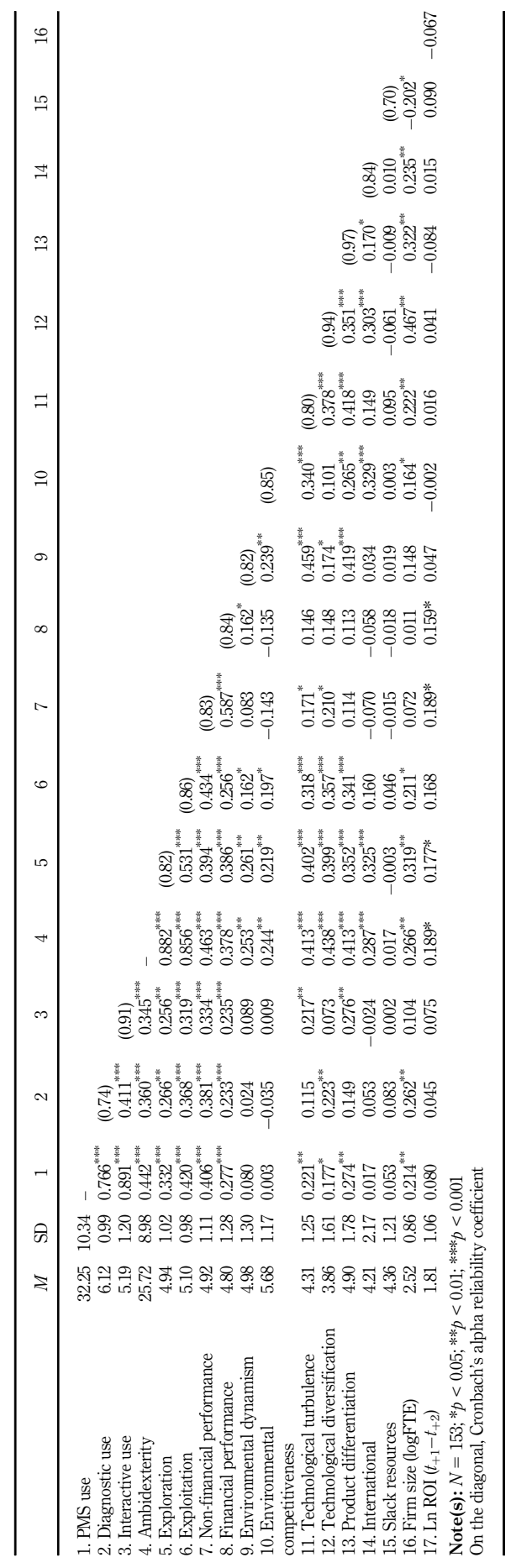

\section{Effects of performance measurement systems}

139

Table 1. Descriptive statistics, correlations and reliability coefficients 


\section{IJOPM 41,13}

\begin{tabular}{|c|c|c|c|c|}
\hline & \multicolumn{2}{|c|}{ Model A } & \multicolumn{2}{|c|}{ Model B } \\
\hline & Beta & $t$-value & Beta & $t$-value \\
\hline \multicolumn{5}{|l|}{ Controls } \\
\hline Firm size & 0.096 & 1.06 & 0.035 & 0.38 \\
\hline Technological diversification & 0.172 & $1.79^{\dagger}$ & 0.129 & 1.36 \\
\hline Product differentiation & 0.185 & $1.90^{\dagger}$ & 0.160 & 1.58 \\
\hline Internationalization & -0.013 & -0.15 & -0.009 & -0.11 \\
\hline Slack resources & 0.051 & 0.64 & 0.016 & 0.21 \\
\hline Environmental dynamism & -0.068 & -0.75 & -0.041 & -0.44 \\
\hline Environmental competitiveness & 0.085 & 0.79 & 0.112 & 1.17 \\
\hline Technological turbulence & 0.188 & 1.49 & 0.167 & 1.41 \\
\hline \multicolumn{5}{|l|}{ Independent variables } \\
\hline Diagnostic & & & 0.298 & $3.51^{* *}$ \\
\hline Interactive & \multirow{2}{*}{\multicolumn{2}{|c|}{0.227}} & 0.031 & 0.31 \\
\hline$R$-square & & & \multicolumn{2}{|c|}{0.314} \\
\hline ANOVA $F$ & \multicolumn{2}{|c|}{$5.241(8,128)^{* * * *}$} & \multirow{2}{*}{\multicolumn{2}{|c|}{$\begin{array}{l}6.516(10,126)^{* * *} \\
7.904(2,126)^{* *}\end{array}$}} \\
\hline$F$ change test & \multicolumn{2}{|c|}{-} & & \\
\hline$N$ & \multicolumn{2}{|l|}{153} & \multicolumn{2}{|c|}{153} \\
\hline \multicolumn{5}{|c|}{ Note(s): ${ }^{\dagger} p<0.10 ; * * p<0.01 ; * * * p<0.001$} \\
\hline
\end{tabular}

Table 2.

OLS regression results for the effects of PMS uses on exploitation

\section{0}

$N$

Note(s): ${ }^{\dagger} p<0.10 ; * * p<0.01 ; * * * p<0.001$

Table 3 shows the regression results for the effects of PMS uses on exploration (H2a, b). Our results do not provide support for H2a. Indeed, a diagnostic use of PMSs is found to positively - rather than negatively, as hypothesized - affect an organization's capacity to explore $(\beta=0.192 ; p<0.001)$. H2b, which expects a positive effect of an interactive use of PMSs on exploration, is not supported.

Considering the control variables proposed, none of them shows statistically significant results (except for firm size and internationalization, which display some effect on exploration).

\begin{tabular}{|c|c|c|c|c|}
\hline & \multicolumn{2}{|c|}{ Model A } & \multicolumn{2}{|c|}{ Model B } \\
\hline & Beta & $t$-value & Beta & $t$-value \\
\hline \multicolumn{5}{|l|}{ Controls } \\
\hline Firm size & -0.118 & $-1.23^{\dagger}$ & -0.155 & $-1.67^{\dagger}$ \\
\hline Technological diversification & 0.188 & 1.73 & 0.171 & 1.59 \\
\hline Product differentiation & 0.184 & $1.99 *$ & 0.139 & 1.48 \\
\hline Internationalization & 0.214 & $2.58^{* * *}$ & 0.222 & $2.73^{* *}$ \\
\hline Slack resources & -0.054 & -0.78 & -0.068 & -0.96 \\
\hline Environmental dynamism & 0.058 & 0.60 & 0.090 & 0.94 \\
\hline Environmental competitiveness & 0.001 & 0.01 & 0.021 & 0.25 \\
\hline Technological turbulence & 0.228 & $2.22^{*}$ & 0.189 & $1.95^{\dagger}$ \\
\hline \multicolumn{5}{|l|}{ Independent variables } \\
\hline Diagnostic & & & 0.175 & $2.37 *$ \\
\hline Interactive & & & 0.107 & 1.22 \\
\hline \multicolumn{5}{|l|}{ Diag. $\times$ Interac } \\
\hline$R$-square & 0.298 & & 0.349 & \\
\hline ANOVA $F$ & $6.66(8$ & & $6.82(1$ & \\
\hline$F$ change test & - & & 4.957( & \\
\hline$N$ & 153 & & 153 & \\
\hline \multicolumn{5}{|c|}{ Note(s): ${ }^{\dagger} p<0.10 ; * p<0.05 ; * * p<0.01 ; * * * p<0.001$} \\
\hline
\end{tabular}

Table 3.

OLS regression results for the effects of PMS uses on exploration

Note(s): ${ }^{\dagger} p<0.10 ;{ }^{*} p<0.05 ; * * p<0.01 ; * * * p<0.001$ 
The third set of hypotheses explores the mediating effect of organizational ambidexterity between PMS uses and firm performance. We followed the procedure proposed by Zhao et al. (2010) that assesses different types of mediations by exploring both direct and indirect effects. Additionally, as suggested by Malhotra et al. (2014), we computed different mediation tests - Sobel, Goodman 1 and 2, and bootstrap - in order to further support our findings. Table 4 reports hierarchical OLS regressions results that assess direct and indirect mediation effects using all three measures of firm performance.

H3a expects a positive direct effect of PMS uses on firm performance (Models B). Both models employing perceptual measures of performance show a positive and significant effect $(\beta=0.415 ; p<0.001$ for non-financial performance and $\beta=0.244 ; p<0.001$ for financial performance), thus providing support to this hypothesis. However, when we employ the lagged accounting data of firm performance, our results show a positive, but not significant relationship $(\beta=0.133 ; p>0.10)$. H3b suggests that the interaction between diagnostic and interactive uses positively affects an organization's capacity to achieve organizational ambidexterity. Our results provide support for this hypothesis $(\beta=0.319 ; p<0.001)$. H3c predicts a positive effect of organizational ambidexterity on firm performance (Models C). All our models using the three different measures of firm performance suggest a positive and significant relationship $(\beta=0.462 ; p<0.001$ for non-financial performance; $\beta=0.360$; $p<0.01$ for financial performance; $\beta=0.257 ; p<0.05$ for lagged accounting data).

Finally, H3d posits that organizational ambidexterity plays a mediating role between PMS uses and firm performance. Following Malhotra et al. (2014), we carried out several tests for the mediation hypothesis employing the three different measures of firm performance (see Table A2 of the Appendix). Both Sobel and Goodman 1 and 2 tests support the mediation hypothesis. A bootstrap analysis was also performed to test the significance of the indirect effect, as suggested by Preacher and Hayes (2004). The mean indirect effect from the bootstrap analysis was found to be positive and significant (values between 0.008 and 0.017 ), with a $95 \%$ confidence interval excluding zero $(0.001-0.031)$. Therefore, our results provide statistical support for the mediation effect using both perceptual measures of firm performance as well as lagged accounting data.

In conclusion, considering the two perceptual measures of firm performance (Table 4), since both the indirect effect (Model C) and the direct effect (Model B) are positive and significant, a complementary mediation of organizational ambidexterity on firm performance is present. When considering the lagged accounting data, since the indirect effect (Model C) is positive and significant, whereas the direct effect is not (Model B), it is possible to conclude that indirect-only mediation is present (Zhao et al., 2010).

\section{Discussion and conclusions}

This study examines the roles of performance measurement system uses, and the dynamic tension generated between them, in promoting the paradoxical framing needed to simultaneously achieve both exploitation and exploration and, ultimately, in enhancing firm performance. In this research, we focused on two different types of uses of PMSs diagnostic and interactive - and operationalized both combined PMS uses and organizational ambidexterity as multidimensional constructs (Birkinshaw and Gupta, 2013; Henri, 2006).

Our results emphasize the crucial role of a diagnostic use of PMS, which, far from acting as a "negative force," appears to be necessary to enable the achievement of operational and strategic goals as well as to guide opportunity search and to establish an appropriate scope for exploration-related activities. Moreover, the relationship between diagnostic and interactive uses emerges not as one of opposing forces, but rather as a synergistic one, which effectively supports the joint pursuit and achievement of exploitation and exploration. This research also shows that PMS uses are positively associated with firm performance, but

\section{Effects of performance measurement systems}


IJOPM
41,13

142

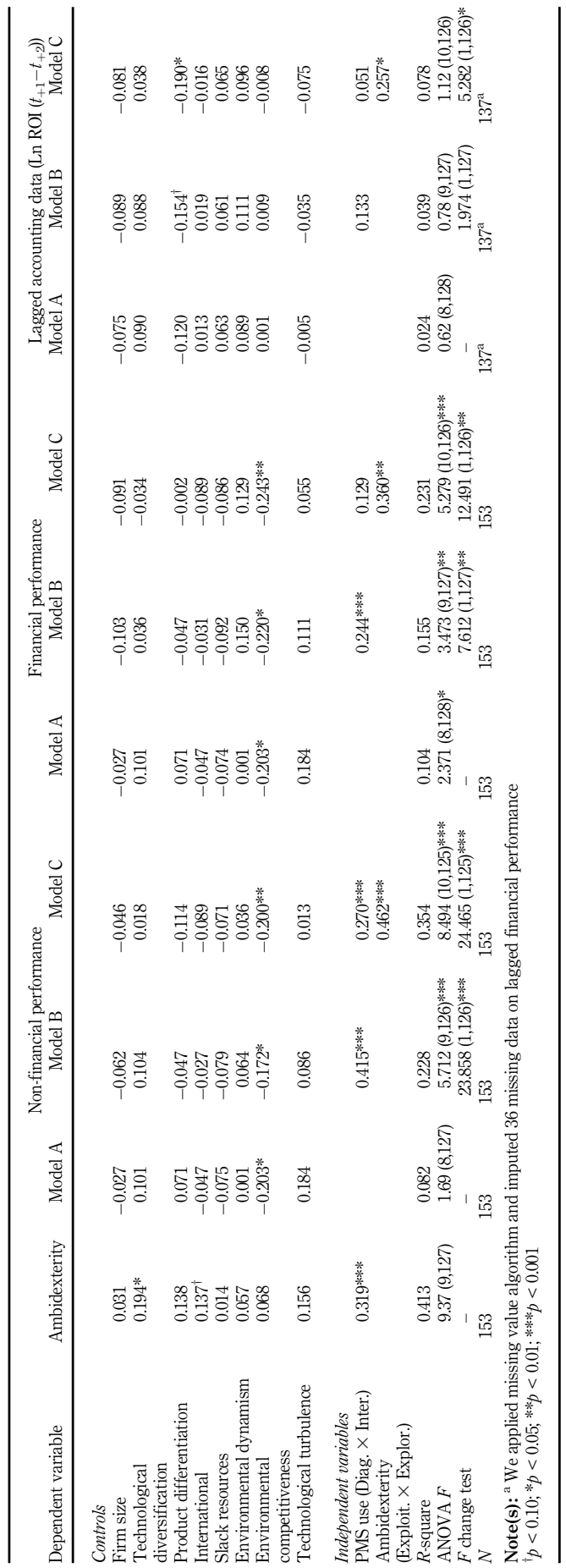

Table 4.

Hierarchical OLS

regressions for testing mediation 
only if an organization is capable of promoting both exploration and exploitation, and that ambidexterity has a positive effect on firm performance. In so doing, this research helps reconcile conflicting views in the literature and extends conclusions drawn in previous studies, leading to several contributions to theory and practice.

\subsection{Theoretical contributions}

First, when examining the relationship between PMS uses and exploitation, we find that a diagnostic use has a positive association, which is in line with studies that considered it as a means to stimulate problem-solving and increase managers' focus on the achievement of operational and strategic goals (Bedford, 2015; Grafton et al., 2010; Melnyk et al., 2004). The effect of the interactive use on exploitation is found to be non-significant, rather than negative, as hypothesized. This may be because, even though the interactive use of PMS is not particularly efficient, as it consumes management time and attention, it also promotes organizational learning, which, in turn, can lead to the improvement of processes and product quality. Nonetheless, these findings suggest that exploitation is best achieved through the diagnostic use only. This type of use, therefore, appears to play a positive role, rather than a negative one (Simons, 1995), in improving current processes and uses of resources.

Second, considering the association between PMS uses and exploration, previous research tends to portray the diagnostic use as a means to create constraints and to ensure compliance with orders, and therefore as a barrier to introducing new processes, technologies and offerings (Henri, 2006; Bititci et al., 2018). Conversely, an interactive use is said to foster capabilities that enhance exploration by focusing managers' attention on strategic priorities and by stimulating dialogue across the organization (Bedford, 2015; Henri and Wouters, 2020). This study challenges these conclusions and adds nuance to these relationships. Specifically, it finds that the diagnostic use has a positive - rather than negative - effect on exploration and that the effect of the sole interactive use is only marginally significant $(\phi$-value $<0.10)$. These results indicate that the effects of the diagnostic use identified in previous studies, such as promoting continuous improvement through single-loop learning (Widener, 2007) and helping improve the innovation process (Müller-Stewens et al., 2020), are likely to play a significantly positive role in both directly supporting the pursuit of exploratory goals and making the interactive use of PMS more effective.

These results, obtained by considering diagnostic and interactive first individually and then jointly, contribute to explaining conflicting findings drawn in previous studies by positioning the diagnostic use as a support for the interactive and as an enabler of innovation. For example, Bisbe and Otley (2004) did not find empirical support for the effect of the interactive use on innovation, whereas Koufteros et al. (2014) did, but also concluded that the diagnostic use was the most constructive explanatory variable for innovation and other capabilities (see also Mundy, 2010). More broadly, this research challenges the adoption of a dichotomic perspective in relation to both the uses and effects of PMSs, and the interplay between exploration and exploitation in line with research on organizational paradoxes (Smith and Lewis, 2011; Schad et al., 2016). In so doing, our results also highlight the importance of stability and formalization for different types of innovation (Jansen et al., 2006) and resonate with conclusions drawn in other studies in operations management. For instance, authors such as Goodale et al. (2011) investigated the moderating effects of operations controls on the relationships between established antecedents of corporate entrepreneurship and innovation performance and found that operations controls enhancerather than reduce - the effects of corporate entrepreneurship on innovation performance. Similarly, some organization theorists have highlighted the positive implications of providing productive constraints, which could facilitate creativity and innovation by acting as "enabling guardrails" (Smith and Besharov, 2019).

\section{Effects of performance measurement systems}


IJOPM

41,13

144

Third, this research has significant implications for wider debates in management and organization theory on the importance of balancing countervailing processes and practices in organizations. In particular, we identify the combination of PMS uses as an important mechanism to foster the achievement of organizational ambidexterity (Raisch and Birkinshaw, 2008): the interplay of diagnostic and interactive uses emerges as a relevant means to create and reinforce a context that enables employees to conduct activities directed at the achievement of current objectives while simultaneously keeping the organization adaptable. This finding supports Gibson and Birkinshaw's (2004) claim that nurturing welldesigned systems and processes enables ambidexterity (see also Kortmann et al., 2014) and challenges the view that "antecedents of exploration undermine exploitation, and vice versa" (Lavie et al., 2010, p. 118). Indeed, over the past two decades, various scholars have claimed that "exploration and exploitation require fundamentally different and inconsistent architectures" (Jansen et al., 2009, p. 798), whereas others have argued that the same processes and systems may enable organizations to pursue both exploration and exploitation (Andriopoulos and Lewis, 2009; Birkinshaw and Gupta, 2013).

Also, our focus on the uses of PMSs, rather than their mere deployment, confirms that ambidexterity is achieved through managerial capability, rather than just through the mere deployment of management systems, like PMS (Birkinshaw and Gupta, 2013). Furthermore, our findings challenge the traditional view of control systems being used solely to monitor and exploit current resources, and to enable top management top-down execution of strategy and plans, which hamper employee autonomy and creativity, eventually reducing the agility organizations need to respond to changes in the external environment (Benner and Tushman, 2015). Our emphasis on the use of measurement systems also enables us to make a contribution to the organization theory literature by showing that PMSs are not necessarily monitoring mechanisms (e.g. Mazmanian and Beckman, 2018), but dynamic systems that can be used in different ways and that can trigger both exploration and exploitation.

Fourth, this research demonstrates that organizational ambidexterity positively impacts firm performance. Notwithstanding the vast number of empirical studies on ambidexterity conducted over the past two decades, the results over the effects of ambidexterity on firm performance are inconclusive (see, e.g. Junni et al., 2013). This study shows that exploration and exploitation can be connected and mutually reinforcing. It also demonstrates that managers are capable of promoting both of them at the same time through the varied uses of PMSs.

Fifth, our study contributes to the literature on the effectiveness of PMSs (Franco-Santos et al., 2012; Micheli and Mura, 2017). Specifically, we find that the association between PMS uses and performance is positive and significant, but it depends on an organization's capacity to pursue and achieve both exploration and exploitation. This finding supports previous research, which found initial evidence of the influence of the dynamic tension between diagnostic and interactive uses of PMSs on performance (Henri, 2006), but identifies a relevant mediating variable. Importantly, our results are significant using both perceptual as done in several previous studies (e.g. Henri, 2006; Grafton et al., 2010) - and accounting data that we collected in the two financial years following our survey.

Finally, from a methodological point of view, our use of lagged accounting data for assessing firm performance represents a contribution to existing research in both performance measurement and management and organizational ambidexterity. Indeed, most studies considering the impact of either PMS uses or ambidexterity on firm performance have used perceptual measures only.

\subsection{Managerial implications}

The findings of this research also have several implications for management practice. If an organization or business unit is mainly pursuing exploitative goals, such as reducing costs or lead times, a mainly diagnostic use of PMSs, whereby results are monitored and progress 
toward the goals is tracked, would be most suitable. On the contrary, an interactive use may not prove particularly effective: future-looking discussions of performance data across hierarchical levels, for instance, may not be advisable. Indeed, in this context, a simpler design of PMS would be more effective (Guenther and Heinicke, 2019). If goals are also explorative for example, when an organization is attempting to introduce radically new products or services - a mix of diagnostic and interactive uses would be most appropriate. In this case, the monitoring of current resources and processes could provide a clear baseline, whereas discussing and challenging data, assumptions and action plans could enable the development of new ideas and offerings. This interplay should be managed carefully so that the benefits of both diagnostic and interactive uses are realized.

These findings highlight that managers need to think carefully about how PMSs are used, rather than mainly about which specific key performance indicators (KPIs) and targets are being deployed. In other words, this study reinforces previous findings, which show that indicators cannot be said to be "right" just by assessing how they are constructed, but also by how they are used, e.g. how performance data are communicated and discussed (see also Pešalj et al., 2018). Moreover, to make the uses of PMSs even more effective, organizations should consider further ways in which to promote exploitation and exploration, for example, by adopting both/and leadership approaches (Andriopoulos and Lewis, 2009), encouraging cross-functional collaboration, and ensuring fit between control systems and team dynamics, such as peer pressure in innovation teams (Khanagha et al., 2021).

\subsection{Limitations and future research}

This study has limitations that call for further research. Although our sample of companies was appropriate to validate the proposed hypotheses, the demographic characteristics of companies and sample size were not appropriate to explore contingencies by means of split-sample analyses. Future studies could examine the effects of PMSs on organizational ambidexterity and on firm performance comparing specific types of organizations (e.g. large companies or $\mathrm{SMEs})$ or the industries in which they operate. For example, previous research finds that organizational ambidexterity has a greater impact on performance, especially in nonmanufacturing industries (Junni et al., 2013): scholars could contrast the roles and effects of PMS uses in manufacturing and in non-manufacturing firms. Moreover, while in this study, none of the control variables shows statistically significant results, explicitly comparing industries with very different characteristics and product lifecycles, e.g. consumer electronics with pharmaceutical, may lead to the identification of further dynamics. Also, while the scales in our survey instrument were already validated in previous studies, it is important to point out that the interactive use of PMSs could be linked to other forms of exploration than those included in our scale (i.e. new products or markets) such as individual work behaviors and other individual-level constructs. Additionally, the respondents of the survey were CEOs, CFOs or managing directors, who may have a good understanding of operational issues, especially in small and medium-sized enterprises, but are likely to have a more strategic focus than other staff members. To investigate more operational issues in performance measurement and management, middle managers and frontline staff could be selected as respondents.

In this study, we focused on the diagnostic and interactive uses only, as these have "had the most pervasive effect on the research agenda that has considered how [PMS] are used" (Chenhall and Moers, 2015, p. 3). Future research could consider all four levers of control, the dynamic tensions among them and how they affect organizational ambidexterity (Simons, 1995). Moreover, while in this research, we have highlighted the importance of PMS use, the quality of PMSs could also be considered, e.g. how KPIs and targets are designed and reviewed. Also, given the emphasis on flexibility and stability in the ambidexterity literature, future studies could concentrate on organizations that have implemented specific approaches, such as lean thinking.

\section{Effects of performance measurement systems}


IJOPM

41,13

\section{6}

Finally, the cross-sectional nature of our data did not allow us to explore time-dependent dynamics in PMS use. Further studies, either survey-based or qualitative, could examine changes in how PMSs are used over time - especially in periods of change, such as the one due to the current COVID-19 pandemic - and whether these enable organizations to shift the balance between exploration and exploitation so as to achieve positive performance outcomes. Indeed, the simultaneous pursuit of exploration and exploitation is not attained through the identification of a mid-point. On the contrary, it entails the search of a dynamic equilibrium through constant motion across opposing forces (Smith and Lewis, 2011), as paradoxes persist and cannot be resolved, and "the interplay between their contradictory and interdependent elements consistently shifts, intensifying tensions and/or opening new possibilities, and triggering responses in an ongoing, iterative process” (Schad et al., 2016, p. 33).

\section{Notes}

1. In this article, in line with Tessier and Otley (2012), by "diagnostic" and "interactive," we denote two different uses, rather than types, of PMSs.

2. Since most data are self-reported, we took several procedural measures to minimize the effect of common method bias on our results. Details of these analyses are reported in Section 5.2.

\section{References}

Andriopoulos, C. and Lewis, M.W. (2009), "Exploitation-exploration tensions and organizational ambidexterity: managing paradoxes of innovation", Organization Science, Vol. 20 No. 4, pp. 696-717.

Bedford, D. (2015), "Management control systems across different modes of innovation: implications for firm performance", Management Accounting Research, Vol. 28, pp. 12-30.

Bedford, D.S., Bisbe, J. and Sweeney, B. (2019), "Performance measurement systems as generators of cognitive conflict in ambidextrous firms", Accounting, Organizations and Society, Vol. 72, pp. 21-37.

Benner, M.J. and Tushman, M.L. (2015), "Reflections on the 2013 decade award-Exploitation, exploration, and process management: the productivity dilemma revisited' ten years later", Academy of Management Review, Vol. 40 No. 4, pp. 497-514.

Birkinshaw, J. and Gupta, K. (2013), "Clarifying the distinctive contribution of ambidexterity to the field of organization studies", Academy of Management Perspectives, Vol. 27 No. 4, pp. 287-298.

Bisbe, J. and Otley, D. (2004), "The effects of the interactive use of management control systems on product innovation”, Accounting, Organizations and Society, Vol. 29 No. 8, pp. 709-737.

Bititci, U., Garengo, P., Dörfler, V. and Nudurupati, S. (2012), "Performance measurement: challenges for tomorrow?", International Journal of Management Reviews, Vol. 14 No. 3, pp. 305-327.

Bititci, U.S., Bourne, M., Cross, J., Nudurupati, S. and Sang, K. (2018), "Towards a theoretical foundation for performance measurement and management", International Journal of Management Reviews, Vol. 20 No. 3, pp. 653-660.

Bourne, M., Mills, J., Wilcox, M., Neely, A. and Platts, K. (2000), "Designing, implementing and updating performance measurement systems", International Journal of Operations and Production Management, Vol. 20 No. 7, pp. 754-771.

Cao, Q., Gedajlovic, E. and Zhang, H. (2009), "Unpacking organizational ambidexterity: dimensions, contingencies, and synergistic effects", Organization Science, Vol. 20 No. 4, pp. 781-796.

Cesaroni, F. (2004), "Technological outsourcing and product diversification: do markets for technology affect firms' strategies?”, Research Policy, Vol. 33, pp. 1547-1564.

Chen, C., Lill, J. and Vance, T. (2020), "Management control system design and employees' autonomous motivation”, Journal of Management Accounting Research, Vol. 32 No. 3, pp. 71-91. 
Chenhall, R. and Moers, F. (2015), "The role of innovation in the evolution of management accounting and its integration into management control", Accounting, Organizations and Society, Vol. 47, pp. 1-13.

Franco-Santos, M., Lucianetti, L. and Bourne, M. (2012), "Contemporary performance measurement systems: a review of their consequences and a framework for research", Management Accounting Research, Vol. 23 No. 2, pp. 79-119.

Gibson, C. and Birkinshaw, J. (2004), "The antecedents, consequences, and mediating role of organizational ambidexterity", Academy of Management Journal, Vol. 47 No. 2, pp. 209-226.

Goodale, C.J., Kuratko, F.D., Hornsby, S.J. and Covin, G.J. (2011), "Operations management and corporate entrepreneurship: the moderating effect of operations control on the antecedents of corporate entrepreneurial activity in relation to innovation performance", Journal of Operations Management, Vol. 29, pp. 116-127.

Grafton, J., Lillis, A. and Widener, S. (2010), "The role of performance measurement and evaluation in building organizational capabilities and performance", Accounting, Organizations and Society, Vol. 35, pp. 689-706.

Guenther, T.W. and Heinicke, A. (2019), "Relationships among types of use, levels of sophistication, and organizational outcomes of performance measurement systems: the crucial role of design choices", Management Accounting Research, Vol. 42, pp. 1-25.

Gupta, A.K., Smith, K.G. and Shalley, C.E. (2006), "The interplay between exploration and exploitation", Academy of Management Journal, Vol. 49 No. 4, pp. 693-706.

Hanson, J.D., Melnyk, S.A. and Calantone, R.A. (2011), "Defining and measuring alignment in performance management", International Journal of Operations and Production Management, Vol. 31 No. 10, pp. 1089-1114.

He, Z.L. and Wong, P.K. (2004), "Exploration vs exploitation: an empirical test of the ambidexterity hypothesis", Organization Science, Vol. 15 No. 4, pp. 481-494.

Heggen, C. and Sridharan, V.G. (2021), "The effects of an enabling approach to eco-control on firms' environmental performance: a research note", Management Accounting Research, Vol. 50, pp. 1-9, doi: 10.1016/j.mar.2020.100724.

Henri, J.F. (2006), "Management control systems and strategy: a resource-based perspective", Accounting, Organizations and Society, Vol. 31 No. 6, pp. 529-558.

Henri, J.F. and Wouters, M. (2020), "Interdependence of management control practices for product innovation: the influence of environmental unpredictability", Accounting, Organizations and Society, Vol. 86, pp. 1-14, Article ID 101073.

Jancenelle, V. (2020), "Relative exploration and firm performance: exploring curvilinear relationships and the role of industry, instability, and munificence", Long Range Planning, Vol. 53 No. 6, p. 101926.

Jansen, J.J.P., van den Bosch, F.A.J. and Volberda, H.W. (2006), "Exploratory innovation, exploitative innovation, and performance: effects of organizational antecedents and environmental moderators", Management Science, Vol. 52 No. 11, pp. 1661-1674.

Jansen, J.J., Tempelaar, M., Van den Bosch, J. and Volberda, H.W. (2009), "Structural differentiation and ambidexterity: the mediating role of integration mechanisms", Organization Science, Vol. 20 No. 4, pp. 797-811.

Jaworski, B.J. and Kohli, A.K. (1993), "Market orientation - antecedents and consequences", Journal of Marketing, Vol. 57 No. 3, pp. 53-70.

Junni, P., Sarala, R.M., Taras, V. and Tarba, S.Y. (2013), "Organizational ambidexterity: a metaanalysis", Academy of Management Perspectives, Vol. 27 No. 4, pp. 299-312.

Khanagha, S., Volberda, H., Alexiou, A. and Annosi, M.C. (2021), "Mitigating the dark side of agile teams: peer pressure, leaders' control, and the innovative output of agile teams", Journal of Product Innovation Management, forthcoming.

\section{Effects of performance measurement systems}


IJOPM

41,13

\section{8}

Kim, J. and Muller, C.V. (1989), Introduction to Factor Analysis, Sage University paper series on Quantitative Applications in the Social Sciences, 07-013, Sage Publications, Beverly Hills, CA.

Kortmann, S., Gelhard, C., Zimmermann, C. and Piller, F.T. (2014), "Linking strategic flexibility and operational efficiency: the mediating role of ambidextrous operational capabilities", Journal of Operations Management, Vol. 32 No. 7, pp. 475-490.

Koufteros, X., Verghese, A. and Lucianetti, L. (2014), "The effect of performance measurement systems on firm performance: a cross-sectional and a longitudinal study", Journal of Operations Management, Vol. 32 No. 6, pp. 313-336.

Lavie, D., Stettner, U. and Tushman, M. (2010), "Exploration and exploitation within and across organizations", The Academy of Management Annals, Vol. 4 No. 1, pp. 109-155.

Lord, M.D. and Ranft, A.L. (2000), "Organizational learning about new international markets: exploring the internal transfer of local market knowledge", Journal of International Business Studies, Vol. 31 No. 4, pp. 573-589.

Lubatkin, M.H., Simsek, Z., Ling, Y. and Veiga, J.F. (2006), "Ambidexterity and performance in small to medium-sized firms: the pivotal role of top management team behavioral integration", Journal of Management, Vol. 32 No. 5, pp. 646-672.

Malhotra, M.J., Singhal, C., Shang, G. and Ployhart, R.E. (2014), "A critical evaluation of alternative methods and paradigms for conducting mediation analysis in operations management research", Journal of Operations Management, Vol. 32 No. 4, pp. 127-137.

March, J.G. (1991), "Exploration and exploitation in organizational learning”, Organization Science, Vol. 2 No. 1, pp. 71-87.

Mazmanian, M. and Beckman, C.M. (2018), “Making' your numbers: engendering organizational control through a ritual of quantification", Organization Science, Vol. 29, pp. 357-379.

Melnyk, S.A., Stewart, D.M. and Swink, M. (2004), "Metrics and performance measurement in operations management: dealing with the metrics maze", Journal of Operations Management, Vol. 22 No. 3, pp. 209-218.

Micheli, P. and Mura, M. (2017), "Executing strategy through comprehensive performance measurement systems", International Journal of Operations and Production Management, Vol. 37 No. 4, pp. 423-443.

Müller-Stewens, B., Widener, S.K., Möller, K. and Steinmann, J.C. (2020), "The role of diagnostic and interactive control uses in innovation", Accounting, Organizations and Society, Vol. 80, pp. 1-21.

Mundy, J. (2010), "Creating dynamic tensions through a balanced use of management control systems", Accounting, Organizations and Society, Vol. 35, pp. 499-523.

Nohria, N. and Gulati, R. (1996), "Is slack good or bad for innovation?", Academy of Management Journal, Vol. 39 No. 5, pp. 1245-1264.

Nunnally, J. (1978), Psychometric Theory, McGraw-Hill, New York, NY.

O'Reilly, G.A. and Tushman, M.L. (2011), "Organizational ambidexterity in action: how managers explore and exploit”, California Management Review, Vol. 53 No. 4, pp. 1-18.

O'Reilly, G.A. and Tushman, M.L. (2013), "Organizational ambidexterity: past, present, and future", Academy of Management Perspectives, Vol. 27 No. 4, pp. 324-338.

Pedersen, E.G. and Sudzina, F. (2012), "Which firms use measures? Internal and external factors shaping the adoption of performance measurement systems in Danish firms", International Journal of Operations and Production Management, Vol. 32 No. 1, pp. 4-27.

Peltokorpi, A., Matinheikki, J., Lehtinen, J. and Rajala, R. (2020), "Revisiting the unholy alliance of health-care operations: payor-provider integration of occupational health services", International Journal of Operations and Production Management, Vol. 40 No. 4, pp. 357-387.

Pešalj, B., Pavlov, A. and Micheli, P. (2018), "The use of management control and performance measurement systems in SMEs: a levers of control perspective", International Journal of Operations and Production Management, Vol. 38 No. 11, pp. 2169-2191. 
Podsakoff, P.M., MacKenzie, S.B., Jeong-Yeon, L. and Podsakoff, N.P. (2003), "Common method biases in behavioral research: a critical review of the literature and recommended remedies", Journal of Applied Psychology, Vol. 88 No. 5, pp. 879-903.

Preacher, K.J. and Hayes, A.F. (2004), "SPSS and SAS procedures for estimating indirect effects in simple mediation models", Behavior Research Methods, Instruments, and Computers, Vol. 36 No. 4, pp. 717-731.

Raisch, S. and Birkinshaw, J. (2008), "Organizational ambidexterity: antecedents, outcomes, and moderators", Journal of Management, Vol. 34 No. 3, pp. 375-409.

Reinartz, W., Krafft, M. and Hoyer, W.D. (2004), "The customer relationship management process: its measurement and impact on performance", Journal of Marketing Research, Vol. 41 No. 3, pp. 293-305.

Rothaermel, F.T. (2001), "Incumbent's advantage through exploiting complementary assets via interfirm cooperation”, Strategic Management Journal, Vol. 22 Nos 6-7, pp. 687-699.

Schad, J., Lewis, M.W., Raisch, S. and Smith, W.K. (2016), "Paradox research in management science: looking back to move forward", The Academy of Management Annals, Vol. 10, pp. 5-64.

Simons, R.A. (1995), Levers of Control: How Managers Use Innovative Control Systems to Drive Strategic Renewal, Harvard Business School Press, Boston, MA.

Smith, W.K. and Besharov, M.L. (2019), "Bowing before dual gods: how structured flexibility sustains organizational hybridity”, Administrative Science Quarterly, Vol. 64 No. 1, pp. 1-44.

Smith, W.K. and Lewis, M.W. (2011), "Toward a theory of paradox: a dynamic equilibrium model of organizing", Academy of Management Review, Vol. 36, pp. 381-403.

Tamayo-Torres, J., Roehrich, J.K. and Lewis, M.A. (2017), "Ambidexterity, performance and environmental dynamism", International Journal of Operations and Production Management, Vol. 37 No. 3, pp. 282-299.

Tessier, S. and Otley, D. (2012), “A conceptual development of Simons' levers of control framework", Management Accounting Research, Vol. 23 No. 3, pp. 171-185.

Uotila, J., Maula, M., Keil, T. and Zahra, S. (2009), "Exploration, exploitation, and financial performance: analysis of S\&P 500 corporations", Strategic Management Journal, Vol. 30 No. 2, pp. 221-231.

Upadhaya, B., Munir, R. and Blount, Y. (2014), "Association between performance measurement systems and organisational effectiveness", International Journal of Operations and Production Management, Vol. 34 No. 7, pp. 853-875.

Villena, V.H., Revilla, E. and Choi, T.Y. (2011), "The dark side of buyer-supplier relationships: a social capital perspective", Journal of Operations Management, Vol. 29, pp. 561-576.

Widener, S.K. (2007), "An empirical analysis of the levers of control framework”, Accounting, Organizations and Society, Vol. 32 Nos 7-8, pp. 757-788.

Zhao, X., Lynch, J.G. Jr and Chen, Q. (2010), "Reconsidering baron and Kenny: myths and truths about mediation analysis", Journal of Consumer Research, Vol. 37 No. 2, pp. 197-206.

\section{Effects of performance measurement systems}


IJOPM

41,13

\section{Appendix}

\begin{tabular}{|c|c|c|c|c|c|c|}
\hline \multirow[b]{2}{*}{ Factors and items } & \multicolumn{6}{|c|}{ Factor loadings } \\
\hline & 1 & 2 & 3 & 4 & 5 & 6 \\
\hline \multicolumn{7}{|l|}{ 1. Diagnostic use } \\
\hline Track progress toward goals & 0.793 & -0.069 & -0.391 & 0.104 & 0.257 & -0.326 \\
\hline Monitor results & 0.997 & -0.014 & -0.322 & -0.042 & -0.081 & 0.195 \\
\hline Compare outcomes to expectations & 0.823 & -0.180 & 0.031 & -0.304 & -0.139 & 0.096 \\
\hline \multicolumn{7}{|l|}{ 2. Interactive use } \\
\hline $\begin{array}{l}\text { Enable discussion in meetings between } \\
\text { managers and employees or among peers }\end{array}$ & -0.019 & 0.806 & -0.027 & -0.050 & -0.089 & 0.135 \\
\hline $\begin{array}{l}\text { Enable continual challenge of underlying } \\
\text { data, assumptions and action plans }\end{array}$ & 0.128 & 0.725 & 0.285 & -0.348 & -0.144 & 0.177 \\
\hline Provide a common view of the organization & -0.130 & 0.887 & -0.036 & 0.142 & 0.054 & 0.048 \\
\hline Tie the organization together & -0.365 & 0.953 & -0.006 & 0.130 & 0.114 & -0.214 \\
\hline $\begin{array}{l}\text { Enable the organization to focus on common } \\
\text { issues }\end{array}$ & 0.069 & 0.766 & 0.146 & -0.107 & 0.002 & -0.066 \\
\hline $\begin{array}{l}\text { Enable the organization to focus on critical } \\
\text { success factors }\end{array}$ & 0.165 & 0.707 & -0.154 & 0.178 & -0.044 & -0.063 \\
\hline $\begin{array}{l}\text { Develop a common vocabulary in the } \\
\text { organization }\end{array}$ & 0.041 & 0.783 & 0.003 & 0.052 & 0.034 & -0.157 \\
\hline \multicolumn{7}{|l|}{ 3. Exploitation } \\
\hline Reduce total costs & -0.059 & 0.013 & 0.985 & -0.460 & -0.212 & 0.275 \\
\hline existing product quality & 0.420 & -0.025 & 0.843 & -0.131 & -0.303 & 0.189 \\
\hline $\mathrm{y}$ of processes & 0.099 & 0.038 & 0.751 & -0.054 & 0.076 & -0.073 \\
\hline Reduce lead time & -0.030 & -0.071 & 0.594 & 0.238 & 0.111 & -0.126 \\
\hline Improve current processes & 0.137 & -0.155 & 0.573 & -0.012 & 0.330 & -0.206 \\
\hline \multicolumn{7}{|l|}{ 4. Exploration } \\
\hline Introduce new gen & 0.030 & 0.047 & 0.063 & 0.825 & -0.195 & \\
\hline Extend product re & -0.053 & 0.010 & -0.138 & 0.896 & -0.225 & 0.258 \\
\hline Open up new markets & -0.249 & 0.041 & -0.365 & 0.960 & 0.067 & -0.009 \\
\hline Enter new technology fields & -0.217 & -0.023 & 0.066 & 0.813 & 0.083 & -0.139 \\
\hline \multicolumn{7}{|l|}{ 5. Non-financial performance } \\
\hline This firm is achieving its full potential & -0.142 & 0.008 & -0.171 & 0.053 & 0.984 & 0.270 \\
\hline $\begin{array}{l}\text { People at my level are satisfied with the level } \\
\text { of firm performance }\end{array}$ & -0.271 & 0.098 & -0.001 & -0.061 & 0.946 & 0.369 \\
\hline $\begin{array}{l}\text { This firm does a good job at satisfying our } \\
\text { customers }\end{array}$ & 0.241 & 0.044 & -0.199 & 0.163 & 0.585 & 0.290 \\
\hline \multicolumn{7}{|l|}{ 6. Financial performance } \\
\hline Attain market shar & 0.175 & -0.034 & 0.036 & 0.055 & 0.272 & 0.744 \\
\hline ales growth & 0.092 & -0.047 & 0.205 & 0.068 & 0.195 & 0.808 \\
\hline Ensure current profitability & 0.030 & 0.023 & 0.326 & -0.087 & 0.229 & 0.670 \\
\hline$\%$ variance extracted & 5.88 & 32.02 & 12.31 & 6.27 & 4.23 & 10.12 \\
\hline Cronbach's $\alpha$ & 0.74 & 0.91 & 0.86 & 0.82 & 0.83 & 0.84 \\
\hline
\end{tabular}

Table A1. EFA

\section{0}




\begin{tabular}{|c|c|c|c|c|}
\hline & $\begin{array}{l}\text { Non-financial performance } \\
\text { Coefficient }(Z)\end{array}$ & $\begin{array}{c}\text { Financial performance } \\
\text { Coefficient }(Z)\end{array}$ & $\begin{array}{l}\text { Lagged accounting data } \\
\text { Coefficient (Z) } \\
\end{array}$ & $\begin{array}{r}\text { measurement } \\
\text { systems }\end{array}$ \\
\hline Sobel & $0.017(3.59) * * * *$ & $0.017(3.20)^{* * *}$ & 0.008 (1.99)* & \\
\hline Goodman 1 & $0.017(3.56)^{* * * *}$ & $0.017(3.16) * *$ & $0.008(1.96)^{*}$ & 151 \\
\hline Goodman 2 & $0.017(3.63)^{* * * *}$ & $0.017(3.23)^{* *}$ & $0.008(2.01)^{*}$ & \\
\hline Bootstrap & $0.017(3.31)^{* *}$ & $0.017(2.61)^{* *}$ & $0.008(2.10)^{*}$ & Table A2. \\
\hline $95 \%$ confidence interval & $0.007-0.027$ & $0.004-0.031$ & $0.001-0.017$ & Additional tests on \\
\hline \multicolumn{4}{|c|}{$\operatorname{Note}(\mathbf{s}): * p<0.05 ; * * p<0.01 ; * * * p<0.001$} & mediation \\
\hline
\end{tabular}

\section{Corresponding author}

Pietro Micheli can be contacted at: pietro.micheli@wbs.ac.uk

For instructions on how to order reprints of this article, please visit our website:

www.emeraldgrouppublishing.com/licensing/reprints.htm

Or contact us for further details: permissions@emeraldinsight.com 